\title{
Health-related quality of life of patients after mechanical valve replacement surgery for rheumatic heart disease in a developing country
}

\author{
Linda J Thomson Mangnall, ${ }^{1,2}$ David W Sibbritt, ${ }^{3}$ Margaret Fry, ${ }^{2,4}$ Melanie Windus, ${ }^{5}$ \\ Robyn D Gallagher ${ }^{6}$
}

${ }^{1}$ Cardiothoracic Surgical and Medical Telemetry Unit, Sydney Adventist Hospital, Wahroonga, Australia ${ }^{2}$ Faculty of Nursing and Midwifery, University of Sydney, Camperdown, New South Wales, Australia ${ }^{3}$ Faculty of Health, University of Technology, Sydney, New South Wales, Australia ${ }^{4}$ University of Technology, Sydney, Broadway, New South Wales, Australia

${ }^{5}$ Flow Manager; Open Heart International Coordinator (Fiji) Sydney Adventist Hospital, Wahroonga, New South Wales, Australia

${ }^{6}$ Charles Perkins Centre and Sydney Nursing School, University of Sydney, Camperdown, New South Wales, Australia

\section{Correspondence to} Linda Thomson-Mangnall, Clifford Tower, Level 9, Butler Cardiothoracic, Medical \& Surgical Cardiac Telemetry Unit, 185 Fox Valley Road, Wahroonga, NSW 2076, Australia;

linda.tm@sah.org.au

Received 30 July 2014 Revised 28 September 2014 Accepted 4 November 2014

\section{CrossMark}

To cite: Thomson Mangnall LJ, Sibbritt DW Fry $\mathrm{M}$, et al. Heart Asia 2014;6:172-178.

doi:10.1136/heartasia-2014010562

\section{ABSTRACT}

Objective To evaluate the health-related quality of life (HRQoL) of people in Fiji $(n=128)$ undergoing heart valve replacement (VR) surgery for rheumatic heart disease (RHD), conducted by Open Heart International.

Methods Patients who had undergone surgery from 1991 to 2009 ( $n=72)$ and patients undergoing surgery for the years 2010-2012 ( $n=56)$ were surveyed prospectively, preoperatively and/or postoperatively (the mean follow-up time 5.9 years) using the standard recall Short-Form 36, V.2 (SF-36v2) HRQoL Survey.

Results The sample had a mean age of 26.7 years and $56 \%(n=72)$ were women. Preoperative HRQoL is impaired but by early postoperative ( 1 year) there is significant improvement across all domains $(p<0.05)$ apart from mental health ( $p=0.081$ ). At mid-term (2 years), HRQoL remained substantially improved from preoperative measurement with mental health now significantly better $(p=0.028)$. However, compared with the early follow-up outcomes, at mid-term physical function ( $p=0.001)$, role-physical $(p=0.002$ ) and role-emotional $(p=0.042)$ domains significantly declined. By late follow-up ( $>2$ years), all HRQoL domains, except for mental health, were significantly better than preoperative $(p=0.066)$. Predictors of less improved HRQoL included having an isolated mitral valve replacement (MVR) (for six of eight health domains, $p<0.05$ ), older age (three domains; rolephysical, vitality and bodily pain, $\mathrm{p}<0.05$ ) and male gender (in the role-emotional domain, $\mathrm{p}<0.05$ ).

Conclusions This first investigation of the HRQoL of people in a developing country after VR surgery for RHD found significant improvement from surgery with this improvement generally sustained. The lack of improvement in mental health requires further exploration as does the influence of an isolated MVR, age and gender.

\section{INTRODUCTION}

The Fiji Islands has the highest documented prevalence of rheumatic heart disease (RHD) in the world and is one of many developing countries where RHD continues to be a significant cause of mortality and morbidity, particularly for young people. ${ }^{1-6}$ RHD is a chronic condition caused by changes to the heart valves that arise as sequela of rheumatic fever. ${ }^{6-8}$ This abnormal valve morphology and increasing cardiac workload lead to worsening cardiac function often eventuating in a need for heart valve replacement (VR) surgery. ${ }^{1} 256910$ Over the past decade, primary and secondary RHD prevention programmes, schoolchildren RHD screening and a national RHD registry have been implemented in Fiji. ${ }^{2}{ }^{71}$ However, there remains an absence of in-country capability to provide VR surgery, with surgical options limited to government or self-funded surgery overseas, or referral to fly-in/fly-out volunteer humanitarian teams' who operate in country. ${ }^{11} 12$

Effectiveness of surgical interventions, such as VR surgery, is traditionally measured on mortality and morbidity outcomes with patient care structured to predefined criterion for consistency in both the management of the condition and the reporting of adverse outcomes. ${ }^{12}{ }^{13}$ However, for the individual patient, the impact of treatment/s on health-related quality of life (HRQoL) is as an important component of effectiveness, as is improvement in symptomatology, functional status and knowledge of mortality and morbidity risk. ${ }^{14}$ Recognising this, the American Heart Association (AHA) recently included HRQoL evaluation as a strategic treatment-impact goal for cardiovascular health. ${ }^{14}$ AHA defined HRQoL as the "discrepancy between actual and desired functional status and overall impact of health on well-being". ${ }^{15}$

A review of literature was undertaken to identify what was known about HRQoL before and after mechanical VR surgery for younger people ( $<65$ years) with a secondary focus on HRQoL outcomes after any VR surgery in developing countries. ${ }^{16}$ Eight papers were identified that focused on younger people ( $<65$ years of age), but few attempted to identify predictors. The literature review provided some limited information indicating that patients, who are younger, and women, experience less improvement in HRQoL. ${ }^{16-18}$ There was a complete absence of published data investigating HRQoL outcomes for people before and/or after VR surgery in developing countries. ${ }^{16}$ Thus, this study was implemented with dual aims: to evaluate the HRQoL of people in Fiji who undergo VR surgery for RHD, conducted by Open Heart International (OHI), Fiji, preoperative and postoperative at early-term, mid-term and late-term follow-up time points; and to identify the independent predictors of postoperative HRQoL.

\section{METHODS}

\section{Design}

This study was of a mixed design with retrospective and prospective recruitment of patients but prospective application of the HRQoL instrumentation at all time points.

\section{Patients}

The study methods have been described elsewhere, ${ }^{19}$ but briefly, all surviving and contactable 
OHI patients who had VR surgery for RHD in the years 19912009, and all patients undergoing surgery during 2010-2012, and aged 12 years or older at the time of survey, were eligible and contacted for inclusion in this study. National and Institutional Human Research Ethics Committee approval was obtained in Australia and Fiji, prior to commencement of the study. All patients were contacted and agreed to participate. Informed consent was obtained before inclusion.

\section{Setting}

The OHI surgical team undertakes VR surgery at the Colonial War Memorial Hospital (CWMH), the national referral hospital located in Suva, Fiji. ${ }^{20}$ Patients are referred by local physicians and screened by an OHI cardiologist 2 months prior to the planned surgical intervention.

\section{Data collection}

Sociodemographic information, New York Heart Association (NYHA) functional score, mortality, morbidity, additional patient contact information and number and timing of HRQoL evaluation/s were recorded at the time of HRQoL survey administration, during six field trips to Fiji over a 3-year period from April 2010 through April 2013. The Australian version of the Short-Form 36, V.2 (SF-36v2) HRQoL Survey ${ }^{20}$ was administered in-person to preoperative participants the day before VR surgery and at 1 year postoperative for the years 2010-2012. Contact with patients who had surgery from 1991 through 2009 was initiated via phone or face-to-face during the OHI advance screening trips, at routine cardiac outpatient clinics at three major metropolitan referral centres or at general health clinics in regional and divisional hospitals on the two main islands, Viti Levu and Vanua Levu. Visits were made to the last known villages of former patients and familial and friendship networks were used to optimise patient follow-up. The HRQoL surveys were interviewer-administered.

\section{Quality of life assessment}

The SF-36 is the most commonly used HRQoL instrument worldwide ${ }^{14152122}$ and is designed to offer a concurrent measurement of physical and mental health status. It comprises 36 specific questions, which are weighted and aggregated to construct eight health domains: physical function; role limitations due to physical health (role-physical); bodily pain; general health; energy/fatigue (vitality); social function; role limitations due to emotional problems (role-emotional) and mental health. ${ }^{22}$ The English-language version of the SF-36v2 is commonly referred to as the 'international version' due to substantial improvements in item wording and terminology from the original SF36. ${ }^{22}$ It comes in standard (4-week recall) and acute (1-week recall) versions with the standard version used in this study. ${ }^{22}$

Raw scores on the SF-36 range from 0 to 100 , with lower scores indicating worse HRQoL. Published data tables of normative scores for raw data can be used to interpret results and are referred to as a 'reference population'. ${ }^{22}$ The Pacific Islander SF-36 mean scores from The National New Zealand (NZ) Health Survey were used as the reference population for this study. ${ }^{23}$

Clinically important differences for $0-100$ scoring, when comparing between studies, are determined using the Statistical Power Analysis tables provided in the SF-36v2 manual. These provide a minimum sample size and associated mean pointscore, by domain, necessary for a clinically important difference and enable evaluation of differences in mean domain scores between two separate groups, in this context, comparing this study data with the NZ Pacific Islander reference population. ${ }^{22}$

The official language of Fiji is English; however, there was an absence of published information on the use of any version of the SF-36 in Fiji. Therefore, prior to commencement of this study, the SF-36v2 was piloted on 20 RHD and VR patients in Fiji. Minor issues in understanding of vernacular were encountered, including 'pep' and examples of the activities on the question "Moderate activities, such as bowling, vacuuming, playing golf", because these are not everyday experiences for most Fijian people. Written authorisation was obtained from the SF-36v2 international licenser ${ }^{24}$ to instead substitute "Moderate activities, such as moving a table, sweeping the floor, swimming, or gardening". Internal consistency reliability (Cronbach's alpha) of the SF-36v2 scores was high: preoperative 0.893; 1 year $0.769 ; 2$ years $0.900 ;>2$ years 0.869 .

\section{Statistical analysis}

Comparisons of patient characteristics between recruited and not-recruited groups were performed using the $\chi^{2}$ test or Fisher's exact test for categorical variables and independent samples $t$ test for continuous variables. A paired $t$ test was used to analyse change in SF-36v2 domain scores from the preoperative survey to the 1-year postoperative survey. Independent samples $t$ test was used to compare the 2-year and greater than 2-year HRQoL measures with the preoperative measures. For longitudinal analysis, the generalised estimating equations (GEE) model was used to determine the relative influence of independent predictors of SF-36v2 domain scores. The GEE models all included the following independent variables: gender, valve location, survey time point and, age at the time of surgery. A $\mathrm{p}$ value $<0.05$ was considered to indicate statistical significance for all analyses. Statistical analyses were conducted using IBM SPSS Statistics (V.18). ${ }^{25}$

\section{RESULTS}

\section{Patient selection}

One hundred and eighty-three patients had VR surgery for RHD by OHI from 1991 to 2012 (figure 1). Of these, all 128 surviving and contactable patients were enrolled in the study. Participants were surveyed preoperative $(n=51)$, and at 1 year postoperative $(n=39)$, and/or at 2 years $(n=19)$, or greater than $2(n=53)$ years, postoperative. Of the non-recruited $(n=55)$ patients, $39(71 \%)$ had died and $16(29 \%)$ were unable to be contacted. The recruited and non-recruited patients differed significantly on gender with more women among the non-recruited $(p=0.024)$, but there were no significant differences by age $(\mathrm{p}=0.485)$ or valve location $(\mathrm{p}=0.249)$.

\section{Patient characteristics}

The mean age of the sample was 26.7 years $(S D=12.4$, range $12-55$ years), just over half were women $(56 \%, n=72)$ and the majority were indigenous Fijian $(62 \%, \mathrm{n}=79)$. Most participants lived in regional $(\mathrm{n}=50)$ or rural $(\mathrm{n}=28)$ areas with a minority $(n=14)$ residing on islands away from the mainlands. At preoperative measurement, two-thirds had NYHA functional class of II, or worse. The most common procedure conducted was isolated mitral valve replacement (MVR) $(56 \%, \mathrm{n}=71)$ followed by isolated aortic valve replacement (AVR) $(19 \%, \mathrm{n}=25)$ with the remainder $(25 \%, \mathrm{n}=32)$ having two or more valves replaced (table 1). 


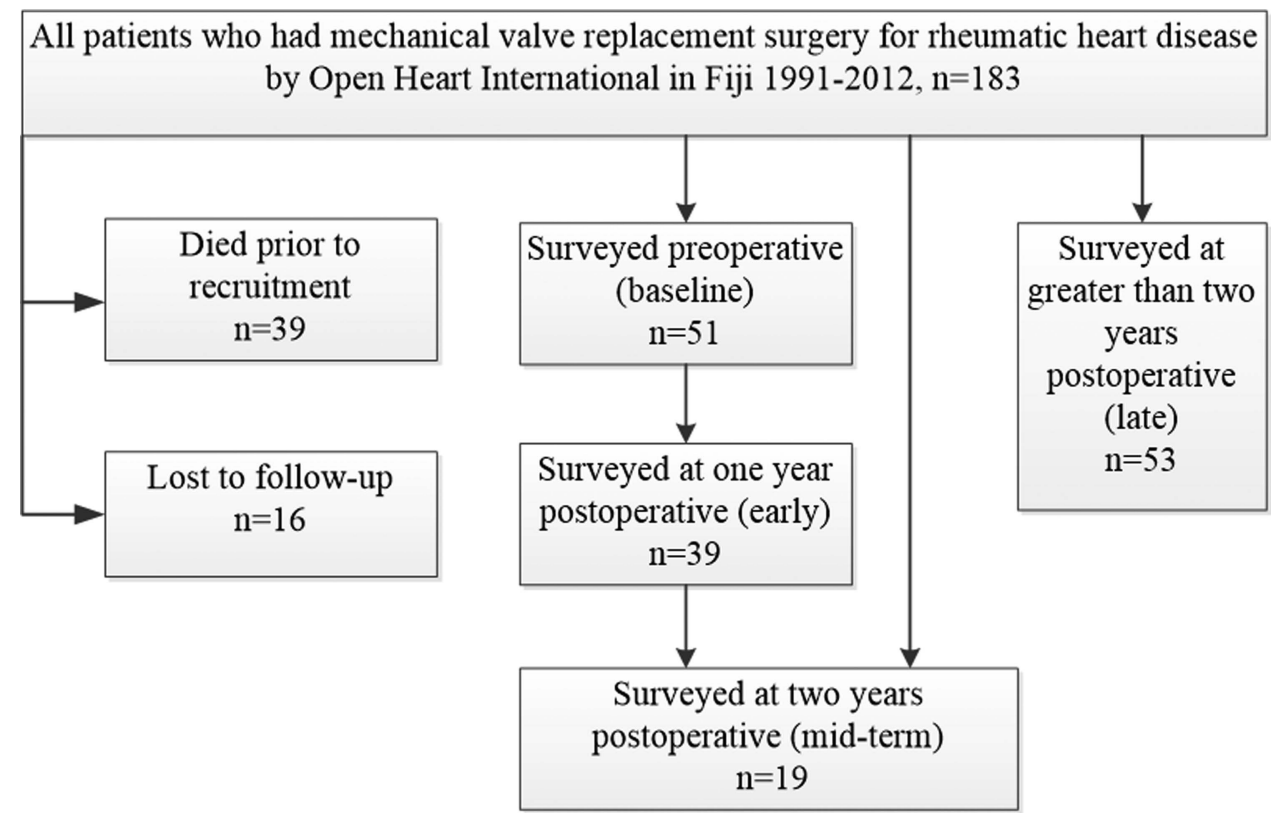

Figure 1 Health-related quality of life recruitment and survey flow diagram for patients who had valve replacement surgery for rheumatic heart disease in Fiji.

\section{HRQoL outcomes}

\section{Preoperative}

Preoperative, there was considerable variation between the HRQoL mean domain scores. The least impacted (ie, highest scoring) domains were bodily pain, role-emotional and mental health and the most impacted (ie, lowest scoring) domains were general health, role-physical and physical function (table 2). However, all mean domain scores were much lower than the reference population (figure 2). Bodily pain and mental health were the domains that scored closest to the reference population

Table 1 Sample characteristics $n=128$

\begin{tabular}{|c|c|c|}
\hline Gender & $\mathbf{n}$ & $(\%)$ \\
\hline Male & 56 & (44) \\
\hline Female & 72 & (56) \\
\hline \multicolumn{3}{|l|}{ Ethnicity } \\
\hline Indigenous Fijian & 79 & (62) \\
\hline Indo-Fijian and Other & 49 & (38) \\
\hline \multicolumn{3}{|l|}{ Valve position } \\
\hline Mitral & 71 & (56) \\
\hline Aortic & 25 & (19) \\
\hline Mitral+Aortic & 22 & (17) \\
\hline Mitral \pm Aortic and tricuspid ring annuloplasty & 10 & (8) \\
\hline \multicolumn{3}{|l|}{ Preoperative NYHA class } \\
\hline NYHA I & 37 & (29) \\
\hline NYHA II & 50 & (39) \\
\hline NYHA III & 32 & (25) \\
\hline NYHA IV & 9 & (7) \\
\hline \multicolumn{3}{|l|}{ Preoperative residential location } \\
\hline Metropolitan & 36 & (28) \\
\hline Regional & 50 & (39) \\
\hline Rural & 28 & (22) \\
\hline Island other than Viti Levu/Vanua Levu & 14 & (11) \\
\hline \multirow[t]{2}{*}{ Age in years at the time of surgery } & Mean & (SD) \\
\hline & 26.66 & (12.48) \\
\hline
\end{tabular}

with general health physical function and role-physical negatively scoring the furthest away from the reference population (figure 2).

All early postoperative (1 year) HRQoL domain mean scores showed improvement (table 2). These changes were significant for seven of the eight domains $(p \leq 0.002)$ with mental health being the exception $(p=0.081)$. When compared with the reference population, early postoperative HRQoL was substantially higher in all domains except mental health which matched the reference population.

\section{Mid-term postoperative ( 2 years)}

At mid-term (2 years), postoperative HRQoL significantly improved from preoperative measurement in seven of eight domains, including mental health $(\mathrm{p}=0.028)$, with the domain of bodily pain no longer showing significant improvement $(p=0.134)$ (table 2). However, when the mid-term postoperative HRQoL scores were compared with the early postoperative HRQoL scores, there was a substantial decrease in role-physical (91.66 to $74.32, p=0.001$ ), role-emotional (91.66 to 78.95 , $\mathrm{p}=0.031$ ) and physical function (95.77 to 85.52, $\mathrm{p}=0.013$ ). When compared with the reference population, mid-term postoperative HRQoL scores were higher in four domains and matched in four domains, but the differences in scores did not reach a clinically important level ${ }^{22}$ (figure 2).

\section{Late postoperative (greater than 2 years)}

Late postoperative HRQoL was measured at a mean of 6.7 years ( $\mathrm{SD}=4.2$ years, range 2.5-19 years). Compared with preoperative measurement, the majority of domains (seven of eight) showed significant improvement, but not the mental health domain $(\mathrm{p}=0.066)$ (table 2$)$. When late postoperative HRQoL scores were compared with mid-term scores, there was no significant difference between these time periods in any domain. Comparison with the reference population showed late HRQoL was higher in the domains of physical function and rolephysical and lower in the domains of general and mental health, but the differences in scores did not reach a clinically important level $^{22}$ (figure 2). 
Table 2 HRQoL SF36 mean domain scores over time $(n=128)$

\begin{tabular}{|c|c|c|c|c|c|c|c|}
\hline \multirow[b]{3}{*}{ Domains } & \multirow{3}{*}{$\begin{array}{l}\text { Preoperative } \\
(n=51) \\
\text { Mean (SD) }\end{array}$} & \multirow{2}{*}{\multicolumn{2}{|c|}{$\begin{array}{l}\text { Early-term } \\
\begin{array}{l}(1 \text { year }) \\
(n=39)\end{array}\end{array}$}} & \multirow{2}{*}{\multicolumn{2}{|c|}{$\begin{array}{l}\text { Mid-term } \\
\text { (2 years) } \\
(n=19)\end{array}$}} & \multirow{2}{*}{\multicolumn{2}{|c|}{$\begin{array}{l}\text { Late-term } \\
\begin{array}{l}(>2 \text { years }) \\
(n=53)\end{array}\end{array}$}} \\
\hline & & & & & & & \\
\hline & & Mean (SD) & p Value* & Mean (SD) & p Valuet & Mean (SD) & p Value $\ddagger$ \\
\hline Physical function & 51.18 (31.66) & $95.77(10.91)$ & 0.001 & 85.52 (19.64) & 0.001 & 87.83 (18.77) & 0.001 \\
\hline Role-physical & $47.30(34.74)$ & 91.66 (16.18) & 0.001 & 74.32 (21.94) & 0.002 & 79.95 (27.91) & 0.001 \\
\hline Bodily pain & $69.02(27.45)$ & 88.82 (13.99) & 0.002 & $79.37(24.18)$ & 0.134 & $79.36(25.53)$ & 0.028 \\
\hline General health & $38.63(25.27)$ & 88.43 (13.98) & 0.001 & $81.74(13.48)$ & 0.001 & $72.77(23.23)$ & 0.001 \\
\hline Vitality & $52.20(23.84)$ & 74.04 (12.87) & 0.001 & $71.70(13.23)$ & 0.001 & $68.16(15.90)$ & 0.001 \\
\hline Social function & $59.07(29.80)$ & 89.74 (13.71) & 0.001 & 84.87 (13.24) & 0.001 & 82.07 (25.89) & 0.001 \\
\hline Role-emotional & $64.70(26.90)$ & $91.66(18.44)$ & 0.001 & $78.95(24.43)$ & 0.042 & 79.09 (26.83) & 0.011 \\
\hline Mental health & 64.61 (16.79) & 73.85 (16.48) & 0.081 & 74.47 (15.52) & 0.028 & 71.98 (19.67) & 0.066 \\
\hline
\end{tabular}

\section{Independent predictors of HRQoL}

GEE modelling was used to determine the factors associated with the SF-36v2 domain scores over time (tables 3 and 4). Postoperative time was the single most consistent, independent, predictor of positive change in HRQoL from the preoperative scores, although these changes were not linear across all time points. At 1 year postoperative, there was a statistically significant improvement across all domains of HRQoL (range: 19-49 points, $p<0.001)$ except for mental health $(p=0.962)$. At 2 years postoperative, there was a statistically significant improvement (range: 16-27, $\mathrm{p}<0.005$ ) in four of the eight domains (physical function, role-physical, general health and vitality), but this time point was a predictor of less improvement
$(-10, p=0.019)$ in mental health. Postoperative time exceeding 2.5 years independently predicted positive change (range: 14-41, $\mathrm{p}<0.02)$ in all domains except bodily pain and mental health.

The location of the VR was also an important predictor of HRQoL. In comparison with an isolated MVR, all other valves led to better HRQoL in the domains of physical function and general health (range: $11-17, \mathrm{p}<0.05$ ). This was less consistent in the other domains. An isolated AVR independently predicted improvement (range: 9-16, $\mathrm{p}<0.036$ ) in all domains apart from role-physical and bodily pain compared with isolated MVR. Tricuspid valve involvement independently predicted improvement in general health of 15 points higher than isolated MVR

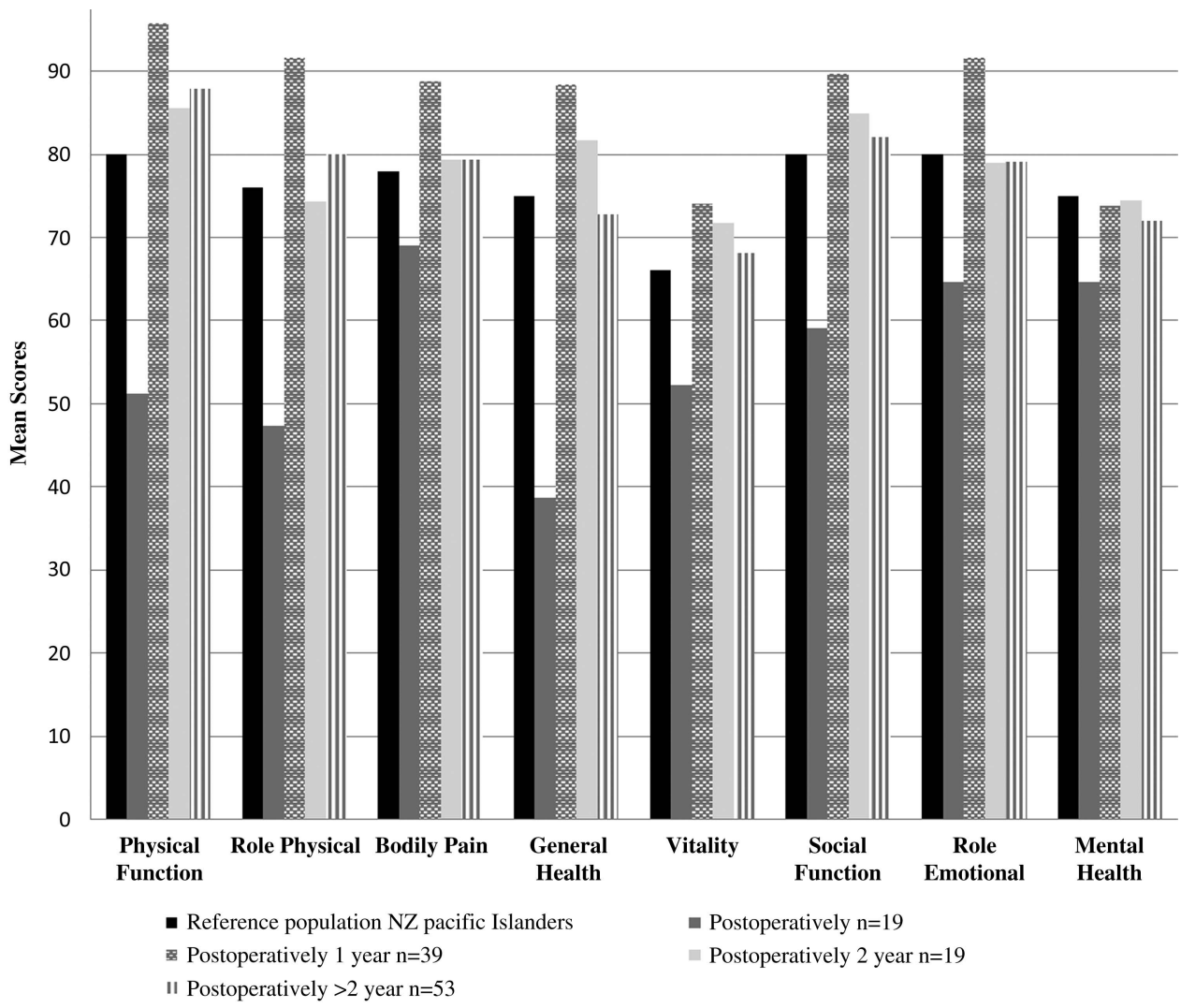

Figure 2 Health-related quality of life domain scores over time, for patients who had valve replacement surgery for rheumatic heart disease in Fiji. 
Table 3 Independent predictors of HRQoL for physical function, role-physical, bodily pain and general health

\begin{tabular}{|c|c|c|c|c|c|c|c|c|c|c|c|c|}
\hline \multirow[b]{2}{*}{ Parameter } & \multirow[b]{2}{*}{ B } & \multicolumn{2}{|c|}{ Physical function $95 \% \mathrm{CI}$} & \multirow[b]{2}{*}{ B } & \multicolumn{2}{|c|}{ Role-physical 95\% Cl } & \multirow[b]{2}{*}{ B } & \multicolumn{2}{|c|}{ Bodily pain $95 \% \mathrm{Cl}$} & \multirow[b]{2}{*}{ B } & \multicolumn{2}{|c|}{ General health $95 \% \mathrm{Cl}$} \\
\hline & & $\begin{array}{l}\text { Lower } \\
\text { Upper }\end{array}$ & $\mathrm{p}$ Value & & $\begin{array}{l}\text { Lower } \\
\text { Upper }\end{array}$ & $\mathrm{p}$ Value & & $\begin{array}{l}\text { Lower } \\
\text { Upper }\end{array}$ & $p$ Value & & $\begin{array}{l}\text { Lower } \\
\text { Upper }\end{array}$ & $\mathrm{p}$ Value \\
\hline (Intercept) & 43.49 & (31.76 to 55.21 ) & 0.01 & 51.61 & (36.18 to 67.05 ) & 0.01 & 79.15 & (67.06 to 91.24 ) & 0.01 & 34.73 & (22.33 to 47.14 ) & 0.01 \\
\hline Male & $0^{*}$ & & & $0^{*}$ & & & $0^{*}$ & & & $0^{*}$ & & \\
\hline Female & 3.59 & (-3.79 to 10.98$)$ & 0.34 & 6.30 & ( -2.51 to 15.11$)$ & 0.16 & 1.42 & $(-6.20$ to 9.04$)$ & 0.72 & 4.90 & $(-2.22$ to 12.01$)$ & 0.18 \\
\hline Mitral & $0^{*}$ & & & $0^{*}$ & & & $0^{*}$ & & & $0^{*}$ & & \\
\hline Tricuspid and Other & 12.62 & $(-0.13$ to 25.36$)$ & 0.05 & -14.28 & $(-29.15$ to 0.60$)$ & 0.06 & -7.30 & $(-21.18$ to 6.59$)$ & 0.30 & 15.24 & (4.00 to 26.47$)$ & 0.01 \\
\hline Aortic and Mitral & 11.61 & (0.20 to 23.01$)$ & 0.05 & 4.38 & $(-7.17$ to 15.94$)$ & 0.46 & -6.00 & $(-17.98$ to 5.97$)$ & 0.33 & 17.47 & (8.53 to 26.41$)$ & 0.01 \\
\hline Aortic & 16.14 & (8.05 to 24.23 ) & 0.01 & 10.90 & (0.59 to 21.21$)$ & 0.04 & 3.51 & $(-4.76$ to 11.78$)$ & 0.41 & 13.78 & (4.82 to 22.73 ) & 0.01 \\
\hline Baseline & $0^{*}$ & & & $0^{*}$ & & & $0^{*}$ & & & $0^{*}$ & & \\
\hline$>2$ years post & 40.93 & (31.72 to 50.14 ) & 0.01 & 32.61 & (20.97 to 44.26 ) & 0.01 & 9.58 & (0.24 to 18.92 ) & 0.04 & 28.96 & (19.72 to 38.20 ) & 0.01 \\
\hline 2 years post & 23.31 & (8.92 to 37.69 ) & 0.01 & 27.66 & (14.57 to 40.75 ) & 0.01 & 0.98 & ( -3.93 to 5.88$)$ & 0.70 & 17.29 & (5.36 to 29.23 ) & 0.01 \\
\hline 1 year post & 49.38 & (41.43 to 57.32 ) & 0.01 & 43.99 & (34.32 to 53.66 ) & 0.01 & 18.98 & (10.63 to 27.34 ) & 0.01 & 38.10 & (28.79 to 47.42 ) & 0.01 \\
\hline Age at $0 p$ & -0.18 & $(-0.49$ to 0.13$)$ & 0.26 & -0.38 & $(-0.70$ to -0.05$)$ & 0.03 & -0.30 & $(-0.59$ to -0.02$)$ & 0.04 & -0.02 & $(-0.33$ to 0.29$)$ & 0.91 \\
\hline
\end{tabular}

*Reference category.

Table 4 Independent predictors of HRQoL for vitality, social function, role-emotional and mental health

\begin{tabular}{|c|c|c|c|c|c|c|c|c|c|c|c|c|}
\hline \multirow[b]{2}{*}{ Parameter } & \multirow[b]{2}{*}{ B } & \multicolumn{2}{|l|}{ Vitality $95 \% \mathrm{Cl}$} & \multirow[b]{2}{*}{ B } & \multicolumn{2}{|c|}{ Social function $95 \% \mathrm{Cl}$} & \multirow[b]{2}{*}{ B } & \multicolumn{2}{|c|}{ Role-emotional 95\% Cl } & \multirow[b]{2}{*}{ B } & \multicolumn{2}{|c|}{ Mental health $95 \% \mathrm{Cl}$} \\
\hline & & $\begin{array}{l}\text { Lower } \\
\text { Upper }\end{array}$ & $p$ Value & & $\begin{array}{l}\text { Lower } \\
\text { Upper }\end{array}$ & $p$ Value & & $\begin{array}{l}\text { Lower } \\
\text { Upper }\end{array}$ & $p$ Value & & $\begin{array}{l}\text { Lower } \\
\text { Upper }\end{array}$ & $p$ Value \\
\hline (Intercept) & 62.26 & (52.70 to 71.82 ) & 0.01 & 55.34 & (41.88 to 68.80 ) & 0.01 & 60.64 & (48.11 to 73.17 ) & 0.01 & 59.79 & (49.61 to 69.98 ) & 0.01 \\
\hline Male & $0^{*}$ & & & $0^{*}$ & & & $0^{*}$ & & & $0^{*}$ & & \\
\hline Female & -3.49 & (-8.91 to 1.92$)$ & 0.21 & 4.06 & (-3.77 to 11.89$)$ & 0.31 & 12.92 & (5.44 to 20.40 ) & 0.01 & 5.46 & (-0.56 to 11.48$)$ & 0.08 \\
\hline Mitral & $0^{*}$ & & & $0^{*}$ & & & $0^{*}$ & & & $0^{*}$ & & \\
\hline Tricuspid and Other & 2.71 & $(-4.36$ to 9.79$)$ & 0.45 & 12.11 & ( -1.50 to 25.72$)$ & 0.08 & -14.20 & $(-28.28$ to -0.12$)$ & 0.05 & 6.09 & $(-2.39$ to 14.56$)$ & 0.16 \\
\hline Aortic and Mitral & 7.05 & $(-0.81$ to 14.92$)$ & 0.08 & 4.79 & $(-7.48$ to 17.07$)$ & 0.44 & 4.87 & $(-5.48$ to 15.22$)$ & 0.36 & 4.71 & (-4.41 to 13.83$)$ & 0.31 \\
\hline Aortic & 4.51 & $(-2.68$ to 11.69$)$ & 0.22 & 16.79 & (8.61 to 24.97 ) & 0.01 & 10.03 & (1.28 to 18.77$)$ & 0.03 & 8.56 & (0.55 to 16.58$)$ & 0.04 \\
\hline Baseline & $0^{*}$ & & & $0^{*}$ & & & $0^{*}$ & & & $0^{*}$ & & \\
\hline$>2$ years post & 15.19 & (8.35 to 22.03 ) & 0.01 & 19.36 & (8.93 to 29.79 ) & 0.01 & 13.77 & (3.77 to 23.76 ) & 0.01 & 2.84 & $(-4.44$ to 10.12$)$ & 0.45 \\
\hline 2 years post & 16.13 & (11.01 to 21.26$)$ & 0.01 & 6.61 & (-3.80 to 17.02$)$ & 0.21 & 10.68 & (-0.89 to 22.26$)$ & 0.07 & -10.17 & $(-18.64$ to -1.69$)$ & 0.02 \\
\hline 1 year post & 21.36 & (16.09 to 26.64 ) & 0.01 & 22.68 & (13.73 to 31.63 ) & 0.01 & 24.98 & (17.04 to 32.92 ) & 0.01 & 0.19 & ( -7.53 to 7.90$)$ & 0.96 \\
\hline Age at $0 p$ & -0.37 & $(-0.59$ to -0.15$)$ & 0.01 & 0.01 & $(-0.33$ to 0.33$)$ & 1.00 & -0.19 & $(-0.52$ to 0.15$)$ & 0.27 & 0.10 & $(-0.14$ to 0.34$)$ & 0.43 \\
\hline
\end{tabular}

*Reference category. 
$(\mathrm{p}=0.008)$ but worse perception in role-emotional $(-14$, $\mathrm{p}=0.048)$.

Age was found to have a significant impact on three of the eight HRQoL domains. Age independently predicted worse postoperative HRQoL in the domains of role-physical $(p=0.025)$, bodily pain $(p=0.038)$ and vitality $(p=0.001)$ : for every year increase in age, there was a one-third point decrease in the HRQoL in these areas. Gender was a significant predictor only in the role-emotional domain, where men had an average of 13 points less improvement than women $(p=0.001)$.

\section{DISCUSSION}

These findings represent the first investigation of the HRQoL for people after VR surgery for RHD in a developing country and revealed that preoperative HRQoL is considerably impaired prior to surgery but improves substantially following surgical intervention. Importantly, the positive impact on HRQoL experienced after VR surgery is sustained over time in most HRQoL domains. A number of factors were identified in this study that independently predicted change in HRQoL. Of these, time since surgery, mitral valve location and age predicted change in three or more HRQoL domains.

One year following surgery, while significant improvement was present in seven domains, all eight domain mean scores matched, or exceeded, those of the normal NZ Pacific Islander reference population. ${ }^{22} 23$ These positive findings contrast to outcomes of a similarly timed investigation of preoperative and postoperative HRQoL in an Australian sample. ${ }^{26}$ Elliott et $a l,{ }^{26}$ found that while undergoing major cardiothoracic surgery resulted in substantial improvement in HRQoL, all of the postoperative HRQoL scores remained significantly impaired when compared with their normal reference population. It is possible that the absence of cardiac surgical options in Fiji and (often) a lengthy period of ill-health prior to surgery may engender an initial enhanced perception of postoperative HRQoL compared with people living with freely available medical and surgical resources and consequently, different expectations following surgery.

It is clear from this research that the period between earlyterm and mid-term postoperative ( 1 and 2 years) is a time where patients may benefit from additional support. While positive outcomes continued through to mid-term (2 years), there was as a decline in mental health from preoperative measurement. Additionally, compared with the early (1 year) postoperative measures, HRQoL significantly decreased in the domains of physical function, role-physical and role-emotional. As HRQoL perception is relative, the decline in these domains may be related to 'recovery-adaptation-reality' in that people having survived the surgery have now also experienced 2 years of living with the lifelong health management requirements associated with a mechanical valve ${ }^{6} 19$ Aspects of mechanical VR health management, in developing countries like Fiji, are often onerous and time-consuming. ${ }^{27}$ For instance, monitoring and regulating anticoagulant medication require monthly clinic visits. Unlike developed countries where appointments are made and time investment is relatively brief, clinic visits in Fiji typically take up a large portion of a day through travel and waiting time: to see the nurse, have venepuncture, obtain results, consult the doctor and attend pharmacy for dispensing of medication prescriptions. Such regular absences from a job, in a country where unemployment affects more than one-third of people, can substantially affect obtaining and maintaining employment. ${ }^{27} 28$

Late ( $>2$ years postoperative) HRQoL results show an apparent resolution of the aspects that have influenced the outcomes at the mid-term time point as comparison between mid-term and long-term showed HRQoL improvement in six of eight domains. However, as the late postoperative HRQoL surveys were once-only measures and consequently are not the same people as at mid-term, the apparent resolution may not be reflective of reality. Nonetheless, these late HRQoL outcomes compare favourably with a similar aged sample of VR patients in Germany evaluated for late HRQoL. ${ }^{29}$ The late HRQoL scores for Fijian sample in this current study were congruent with Aicher et al, ${ }^{29}$ outcomes across all domains with general health (mean 57 vs 72 ) and vitality (mean 52 vs 68) exceeding the scores of Aicher et $a l^{29}$ sample at a clinically significant level. ${ }^{22}$

An isolated MVR as a predictor of less improved postoperative HRQoL has not previously been identified in the literature but is not an altogether unexpected finding. This is because mitral stenosis (MS) (as opposed to mitral regurgitation) is often indicative of more advanced RHD and consequently, the likelihood of a worse physical and emotional state is plausible. $^{6}{ }^{30}$ Importantly, an increased incidence of atrial fibrillation (AF) occurs in the presence of MS with approximately $60 \%$ of people with MS valves aged between 21 and 50 years of age diagnosed with $\mathrm{AF}^{3132}$ Living with AF, even if asymptomatic, is known to negatively impact on HRQoL, ${ }^{33}$ but it remains unknown if the AF HRQoL effect is isolated, or multiplicative, in the presence of RHD MS. As data on AF and the specifics of individual valvular disease were absent from patient records, it was impossible to determine if MS and/or the concurrence of $\mathrm{AF}$ are implicated as physiological reasons for this finding. Further investigation is clearly indicated to better understand why people undergoing isolated MVR have less improvement in HRQoL than other isolated or combination valve locations.

Older age as an independent predictor of worsening HRQoL over time was an unexpected finding. It is well recognised in literature that older people generally perceive HRQoL as better than younger people, including in cardiac patient populations, ${ }^{34-36}$ due in part to the evolving expectations of life that occur as people age. ${ }^{34}$ An explanation may lay in the fact that age as an independent predictor in this current study is on a scale so that for every year increase in age, there is a one-third point reduction in perceived HRQoL but with a mean age of 27 years, 'older age' in this sample takes on a different perspective. Further research is required to better inform these findings.

\section{Study limitations}

The findings from this study may not be representative of all patients having VR for RHD as the study only included one surgical programme. The HRQoL measure (SF-36v2) is untested in the Fijian population and requires further evaluation and as a generic measure, additional questions or instrumentation exploring the association between valve-specific health needs such as anticoagulation monitoring, regular clinic attendance and RHD prophylaxis on HRQoL is indicated to gain a greater understanding of how people in Fiji experience life after VR for RHD. Additionally, data that may influence HRQoL such as AF, disease severity (in the form of preoperative and postoperative echocardiographic data and postoperative NYHA) and sociodemographic data such as resumption of schooling, return to work or gaining of employment were not available or incomplete for most patients.

\section{CONCLUSION}

Patients who receive VR surgery for RHD by OHI in Fiji experience substantial improvement in HLQoL. While these improvements are generally sustained over time, we have identified a need for support and for further investigation for patients 
between the early-term and mid-term time points; particularly as mental health was identified as a concern at this time. HRQoL is an important outcome of the effectiveness of any intervention. Consequently, this research is the first step in building a body of knowledge regarding HRQoL after VR surgery for RHD, for younger people, in developing countries.

\section{Declaration of conflicting interests}

The authors declare that there is no conflict of interest.

Contributors LITM contributed as primary investigator and writer and contributed to literature search, literature review, figures, study design, data collection, data entry, data analysis, data interpretation and HREC approval/s. DWS contributed to the statistical analyses and development of results and discussion. He revised the manuscript drafts. MF contributed to overall study design, literature review, methods and development and review of the manuscript. MW contributed to the research plan, implementation, logistics, data collection, data entry and review of the manuscript. RDG contributed to the literature review, methods, analysis and development of the results and discussion. She revised manuscript drafts.

\section{Competing interests None.}

Ethics approval The Sydney Adventist Hospital HREC, The University of Technology HREC and The Fiji National Health Research Ethics Review Committee.

Provenance and peer review Not commissioned; externally peer reviewed.

Data sharing statement All contributing authors have access to the original data files in SPSS format.

\section{REFERENCES}

1 Singh PIPK, Carapetis JR, Buadromo EM, et al. The high burden of rheumatic heart disease found on autopsy in Fiji. Cardiol Young 2008;18:62-9.

2 Reeves BM, Kado J, Brook M, et al. High prevalence of rheumatic heart disease in Fiji detected by echocardiography screening. J PaediatrChild Health 2011;47:473-8.

3 Viali S, Saena P, Futi V. Rheumatic fever programme in Samoa. N Z Med J 2011;124:26-35.

4 Viali S, Viali S. Rheumatic fever and rheumatic heart disease in Samoa. Pac Health Dialog 2006;13:31-8.

5 Steer AC, Kado J, Jenney AWJ, et al. Acute rheumatic fever and rheumatic heart disease in Fiji: prospective surveillance, 2005-2007. Med J Aust 2009;190:133-5.

6 Wyber R, Grainger Gasser A, Thompson D, et al. Tools for implementing RHD control programmes (TIPS) handbook. Perth, Australia: World Heart Federation and RhEACH, 2014.

7 Steer $A$, Colquhoun $S$, Noonan $S$, et al. Control of rheumatic heart disease in the Pacific region. Pac Health Dialog 2006;13:49-55.

8 Soma Raju B, Turi ZG. Rheumatic Fever. In: Bonow RO, Mann DL, Zipes DP, et al., eds. Braunwald's heart disease a textbook of cardiovascular medicine. Philadelphia, PA Elsevier Saunders, 2012:1868-75.

9 Steer AC, Carapetis JR, Nolan TM, et al. Systematic review of rheumatic heart disease prevalence in children in developing countries: the role of environmental factors. [see comment]. J Paediatr Child Health 2002;38:229-34.

10 World Health Organization. WHO Expert Consultation on Rheumatic Fever and Rheumatic Heart Disease. 29 October-1 November 2001 WHO technical report series; 9232004

11 Cuboni HD, Finau SA, Cuboni G. Rheumatic fever and rheumatic heart diseases in Fiji: a review from the surveillance system (1996-2000). Pac Health Dialog 2006;13:39-47.

12 Bonow RO, Carabello BA, Chatterjee K, et al. 2008 Focused update incorporated into the ACC/AHA 2006 guidelines for the management of patients with valvular heart disease: a report of the American College of Cardiology/American Heart Association Task Force on Practice Guidelines (Writing Committee to Revise the 1998 Guidelines for the Management of Patients With Valvular Heart Disease): endorsed by the Society of Cardiovascular Anesthesiologists, Society for
Cardiovascular Angiography and Interventions, and Society of Thoracic Surgeons. Circulation 2008:118:e523-661.

13 van Gameren M, Piazza N, Bogers AJ, et al. How to assess risks of valve surgery: quality, implementation and future of risk models. Heart 2009;95:1958-63.

14 Lloyd-Jones DM, Hong Y, Labarthe D, et al. Defining and setting national goals for cardiovascular health promotion and disease reduction: the American Heart Association's strategic Impact Goal through 2020 and beyond. Circulation 2010;121:586-613.

15 Rumsfeld JS, Alexander KP, Goff DC Jr, et al. Cardiovascular health: the importance of measuring patient-reported health status: a scientific statement from the American Heart Association. Circulation 2013;127:2233-49.

16 Thomson Mangnall $\mathrm{L}$, Sibbritt DW, Gallagher RD, et al. Health-related quality of life of patients after mechanical valve replacement surgery: an integrative review. Eur J Cardiovasc Nurs Published Online First: 15 Mar 2014. doi:10.1177/ 1474515114528126

17 Koertke $H$, Hoffmann-Koch A, Boethig D, et al. Does the noise of mechanical heart valve prostheses affect quality of life as measured by the SF-36 questionnaire? Eur I Cardiothorac Surg 2003;24:52-7; discussion 7-8.

18 van Doorn $C$, Yates $R$, Tunstill $A$, et al. Quality of life in children following mitral valve replacement. Heart 2000;84:643-7.

19 Thomson Mangnall L, Sibbritt D, Fry M, et al. Short- and long-term outcomes after valve replacement surgery for rheumatic heart disease in the South Pacific, conducted by a fly-in/fly-out humanitarian surgical team: a 20-year retrospective study for the years 1991-2011. J Thorac Cardiovasc Surg 2014;148:1996-2003.

20 Were M. Healthcare outreach: about Open Heart International. Sydney, Australia: Sydney Adventist Hospital, Healthcare Outreach, Open Heart International, 2014.

21 Bowling A. Measuring health: a review of quality of life measurement scales. Maidenhead, Berks: Open University Press, 2005.

22 Ware JE Jr, Kosinski M, Bjorner JB, et al. User's manual for the SF-36v2® Health Survey, 2nd edn. Lincoln, RI: QualityMetric Incorporated, 2007.

23 SF-36 Health Status Questionnaire. Demographic and socioeconomic variables. In: Hauora NZMoH-M, ed. Taking the pulse-the 1996/97 New Zealand Health Survey. New Zealand Government, 1999:139-66.

24 Incorporated Q. SF-36v2 Health Survey (SF-36v2). 24 Albion Road Building 400 Lincoln, RI 02865 Medical Outcomes Trust \& QualityMetric Incorporated 2007.

25 PASW Statistics, Chicago, IL, USA: SPSS Inc, 2009.

26 Elliott $D$, Lazarus $R$, Leeder SR. Health outcomes of patients undergoing cardiac surgery: repeated measures using Short Form-36 and 15 Dimensions of Quality of Life questionnaire. Heart Lung 2006:35:245-1.

27 World Health Organization. Primary health care: Fiji's broken dream. Bull World Health Organ 2008;86:166-7.

28 World Health Organization. Fiji: Health Situation and Trend, 2009;2009.

29 Aicher D, Holz A, Feldner S, et al. Quality of life after aortic valve surgery: replacement versus reconstruction. J Thorac Cardiovasc Surg 2011;142:e19-24.

30 Zakkar M, Amirak E, Chan KMJ, et al. Rheumatic mitral valve disease: current surgical status. Prog Cardiovasc Dis 2009;51:478-1.

31 Otto CM, Bonow RO. Valvular heart disease. In: Bonow RO, Mann DL, Zipes DP, et al., eds. Braunwald's heart disease: a textbook of cardiovascular medicine. Philadelphia, PA, USA: Saunders, an imprint of Elsevier Inc. International Edition, 2012:2048

32 Carabello BA. Modern management of mitral stenosis. Circulation 2005;112: 432-7.

33 Fuster V, Rydén LE, Cannom DS, et al. 2011 ACCF/AHA/HRS Focused Updates Incorporated Into the ACC/AHA/ESC 2006 Guidelines for the Management of Patients With Atrial Fibrillation: a report of the American College of Cardiology Foundation/American Heart Association Task Force on Practice Guidelines. Circulation 2011:123:e269-367.

34 Moser DK, Heo S, Lee KS, et al. 'It could be worse...lot's worse!' Why health-related quality of life is better in older compared with younger individuals with heart failure. Age \& Ageing 2013;42:626-32.

35 Grady KL, Lee $\mathrm{R}$, Subacius $\mathrm{H}$, et al. Improvements in health-related quality of life before and after isolated cardiac operations. Ann Thorac Surg 2011;91:777-83.

36 Nugteren LB, Sandau KE. Critical review of health-related quality of life studies of patients with aortic stenosis. J Cardiovasc Nurs 2010;25:25-39. 